\title{
Reform of hospital financing in Austria: successes, failures, and the way forward
}

\author{
Engelbert Theurl
}

Published online: 17 October 2014

(C) Springer-Verlag Berlin Heidelberg 2014

\section{Introduction}

Payment schedules of health care providers constitute an important element of governance structure of every health care system. They provide incentives for service providers, influence the income distribution between them, and shape the risk distribution between the providers, financing institutions, and patients; they also affect the transaction costs of 'running the system'. As far as hospital financing is concerned, we have observed a fundamental change in many countries over the last 25 years. Financing schemes based on the number of patient days and enriched with strong retrospective elements have been substituted by more prospective and activity/case mix-based ones. Austria is no exception in this regard. In 1997, a DRG-based hospital financing system called 'Leistungsorientierte Krankenhausfinanzierung' (henceforth LKF1997) replaced the per diem-based one enriched with very strong retrospective elements.

In this editorial, we describe the historical heritage and basic governance structure of actual hospital financing in Austria, describe the most important building blocks of LKF1997, analyse its successes, and point out the handicaps, that is, the respectively selected 'things-to-do' in the midterm future. Before doing this, we have to mention two restrictions. First, we focus on the financing of only the public part of inpatient medical services. We do not consider the financing of (1) private hospitals, (2) long-term care, and (3) medical education and research [1]. Second, sound and uncontroversial empirical evidence on the effects of the new

E. Theurl $(\bowtie)$

Department of Economics and Statistics, University of Innsbruck, Universitaetsstrasse 15, 6020 Innsbruck, Austria e-mail: engelbert.theurl@uibk.ac.at financing system on hospital performance is scarce in the literature. Therefore, we have to rely on a mix of limited empirical evidence, anecdotic narratives, and expectations from economic theories. However, the overall assessment of LKF1997 is aggravated by the fact that there is no homogeneous hospital financing system in Austria.

\section{Basic governance design and historical heritage}

Hospital financing in Austria is based on a broad setting of political and bureaucratic governance structures [1-3]. The most far-reaching one is the splitting of assignments of regulative power in the health care sector between the central state and the states fixed by the Austrian constitution. Matters relating to the health care system (e.g. social and private health insurance, medical education, disease prevention, and medical service quality) are mainly subjects of the central state, but with one important exception. Inpatient care is regulated by the central state only in its fundamentals; the regulation of details and implementation are left to the states. As far as the outpatient sector is concerned, the role of the central state is mainly regulatory. The management of outpatient care is delegated to the social health insurance system, usually organised by representatives of employers and employees, and to the chamber of physicians. These agents, authorised by obligatory membership, act as monopolists on their 'market side' and interact in a bilateral monopoly manner. This constitutional setting, combined with the peculiarities and imponderables of specific historical developments, has important consequences for the organisation and financing of inpatient care in Austria [1, 2]. Inpatient and outpatient care is organised and financed in two different political and regulatory circuits. While outpatient care is dominated by 
autonomous public institutions, the states play a significant role in inpatient care. Social health insurance is the only source of finance for public outpatient care, but public inpatient care is financed by the social health insurance system, the states, local communities, and the federal state. With regard to reimbursement of medical costs, social health insurance covers only a part of the running costs of hospitals and leaves the financing of investments and deficits to the other co-financers (including the public hospital owners). This 'systemic deficit' creates strong retrospective elements in the hospital financing system.

The two regulatory circuits promote manifold 'beggar my neighbour' policies between the two sectors and hamper the management of interfaces between the different stages of service provision heavily (e.g. gatekeeping, disease management). Hospital management in Austria followed the traditional bureaucratic principles for a long time [1, 2]. Therefore, hospital financing was an integral element of public budgeting. Reform initiatives in the nine states of Austria, starting in the 1980s, led to different forms of outsourcing and institutional autonomy in the public hospital system. These reform initiatives were mainly based on principles of higher flexibility in resource management and advantages in the procurement market. The transformation from an 'integrated model' to a 'contract model' in the hospital sector, symptomatic of an 'internal market concept', was not the focus of this reform movement [4].

The Austrian health care sector is traditionally characterised by an important role for hospital ambulances. To some extent, hospital ambulances act as a gatekeeper to the inpatient sector and provide emergency services. In addition, they closely substitute the public outpatient care offered by registered doctors/specialists on contract with the social health insurance system. This important role of hospital ambulances comes with a specific structure of the (public) outpatient sector in Austria. Economically, the role of the outpatient sector can be characterised as a 'cottage' industry dominated by sole proprietorship; integrated and cooperative forms of health care (e.g. group practices, health maintenance organisations) are significantly underdeveloped or do not exist. The same is true of the role of non-physician professionals (e.g. nurses, health care workers) in outpatient medical treatment and the significance of patient guidance in Managed Care mechanisms. Studies widely agree that these two characteristics are responsible for the high hospital utilisation rates in Austria and the low potential for substituting inpatient care by outpatient care $[1,2,5,6]$.

\section{Reforms of hospital financing since 1997}

Following several minor reforms of the hospital system during the 1970s and 1980s (e.g. defining hospital types more precisely, implementing a hierarchical hospital system, increasing the responsibility of states to guarantee inpatient services), a major reform of the hospital sector was implemented in 1997 [1-3]. The focus of this initiative was the reform of hospital financing, but this was accompanied by reforms in several other building blocks of the governance structure. The reform changed the relationship between the central state and the states [1]. On the one hand, the central state's role in fixing nationwide standards for hospital care (e.g. capacity of beds and technical equipment) was strengthened. On the other hand, the autonomy of states in running hospitals was enhanced and Health Funds supervised and managed by Health Platforms were implemented at the state level. These Health Platforms, consisting of members from the federal government, state government, social health insurance system, chamber of physicians, hospital owners, and local governments, are the most important actors in terms of actual implementation of hospital policy.

The financing of public inpatient care in Austria is clustered in the Health Fund, which acts as a financing institution for public hospitals at the state level. The sources of financing are regulated at the federal level through constitutional treaties. The central state, states, local communities, and social health insurance system finance a nationwide hospital budget allocated to the Health Funds at the state level based on state quotas. The health insurance system pays a lump sum to the hospital budget, which is totally independent of the activity level of hospital systems. Any change in this payment over time is tied to changes in revenue of the health insurance system. The contributions of the central state, states, and local communities are a fixed percentage of their revenue share of value-added tax based on general fiscal equalisation mechanisms [5].

The LKF1997 focusses on a DRG-based form of hospital financing. Since a detailed review of the system is beyond the scope of this article, we will just point out certain selected singularities of the system (for more details and international comparisons, see [5-8]). LKF1997 is a self-developed system not derived from the original DRG system developed at Yale University and implemented in the USA. From a European perspective, LKF1997 is part of the first wave of DRG implementation (along with France, the UK, and the Nordic countries [6]). The spectrum of diseases covered by DRG-based financing is quite comprehensive by international comparison. The number of diagnostic categories used is compared to other DRG systems in a similar range [5, 6]. It increased slightly during the 1997-2014 period. The patient classification system is based on different procedures and diagnoses. Compared to other countries, the procedure-based part of patient categories seems to be high and increases over time. 
Day cases are not identified explicitly as part of the classification process, but form a special group for reimbursement purposes. Unlike other DRG systems, information about the characteristics of patients (e.g. admission and discharge type, age, gender) is considered in the classification process only for age. Additional information on resource consumption is incorporated from the information on stay in specialised departments (e.g. intensive care units). The number of severity levels is not limited. Side diagnoses and complication and comorbidity levels do not influence the severity level. No additional tool exists to adjust for specific high-cost services and potential cost outliers directly; only the length of stay is considered in this context.

Remuneration scores are based on information from reference hospitals and include a procedure-related component and a day component. The day component is a fixed score in a predefined range of length of stay enriched by adjustments for long-stay and short-term outliers [1, 5]. The scores do not include capital costs, and the system does not pay special attention to transfers between hospitals and readmissions. No mandatory cost accounting with national costing guidelines exists. LKF1997 consists of a core area and a steering area. The core area consists of the nationwide homogeneous patient classification system and the scores derived therefrom. The steering area is state specific. When LKF1997 was introduced, the idea of steering area was (1) to allow for quality-related payments and (2) enable transition to DRG-based payment systems. In fact, states presently use the steering area for very different purposes (e.g. additional payments for university hospitals).

The allocation of resources from the state Health Funds to the core and steering areas is state specific. In two states (Upper Austria and Lower Austria), no steering area exists at all and the whole budget is distributed based on scores. Four states (Tyrol, Burgenland, Vorarlberg, and Salzburg) use fixed shares for the two areas, while Carinthia, Styria, and Vienna apply variable rules. The monetary value of the scores is then determined by dividing the available budget for DRG-based payments within states by the total adjusted scores produced by all hospitals. Because of different budget quotas for the states and different rules for dividing the budget between the core and steering areas, the implicit monetary value of the scores differs widely between the states. On a nationwide average, two-thirds of the inpatient costs are covered by the LKF core area scheme, but the shares vary widely between the states from approximately 50-85 \% [6]. Payments from the Health Funds based on LKF1997, including the core and steering areas, do not cover total costs. Therefore, in the new financing system, there is a need for deficit coverage. These rules are state specific [6]. In some states, the deficit coverage is part of the budget of Health Funds, whereas in others the deficit coverage is financed from outside the Health Fund. However, deficit financing is much more prospective than the old system, leaving higher financial risks to the hospital owners. Financing the medical services of hospital ambulances is not part of LKF1997, but is regulated in different ways by the states (e.g. activity-based remuneration following a DRG-approach, lump-sum payment).

\section{Effects of financing reform-selected evidence}

The constitutional convention between the federal states and states on LKF1997 [6] postulates the following as specific goals of financing reform:

1. Improvement in transparency of costs and activities.

2. Sustainable containment of the increase in hospital costs.

3. Optimising resource use.

4. Reduction of unnecessary services (e.g. avoidance of unnecessary medical duplication).

5. Decrease in the length of stay and probability of hospital admission.

6. Substitution of inpatient care with outpatient care whenever possible from a medical point of view and when rewarding from an economic point of view.

7. Carrying out necessary changes in the service structure.

8. Establishment of nationwide homogeneous tools of health policy planning and management.

From this catalogue, we give a short assessment of the current system of hospital financing. We subsume the goals of LKF1997 under broader labels of macro-efficiency of the hospital system (a-e) and macro-efficiency of the total health care system $(\mathrm{e}-\mathrm{h})[1,2,6]$.

\section{Macro-efficiency of the hospital system}

Several studies [1, 2, 5, 6] widely agree that LKF1997 substantially increases the transparency of hospital activities (e.g. services, costs) within hospitals, between hospitals, and also between the hospital systems of the different states. This is an important precondition to creating a common platform of communication and exchange among health professionals, hospital managements, hospital owners, and the health policy stakeholders (e.g. the actors in Health Funds at the state level) and reducing the transaction costs at the different levels of hospital management. This is an important merit in a system with highly particularised responsibilities and a high affinity to consensual decision making. 
Our assessment of goal b (sustainable containment of increase in hospital costs) is mixed. One has to ask whether this is a reasonable goal of the hospital system at all. One could at least argue that it is an instrument to reduce $\mathrm{X}$-inefficiency in the hospital system. From a broader perspective of financing, this goal might increase the competitiveness of an economy and reduce any excess burden inherent in the financing system. The increase in public expenditure for inpatient care during the 1990-1997 period compared to $1998-2012$ is slightly higher $(6.1 \%$ annual change compared to $4.8 \%$ ) and more volatile. The share of public expenditure for inpatient care as a percentage of GDP increases from $2.6 \%$ in 1990 to $3.2 \%$ in 1997, and from $3.2 \%$ in 1998 to $3.8 \%$ in 2012 [8]. The moderate stabilisation of increase in expenditure is not a merit of the DRG part of LKF1997, but is primarily indebted to the formulas of revenue change over time for the contributions of states, the central state, and the social health insurance system.

Overall, LKF1997 does not change the high affinity of the Austrian health care system to the hospital system (goals c-e). The hospital bed density decreased by $14 \%$ during the 1997-2011/12 period. However, in an international comparison, both figures are more than $50 \%$ above the OECD average. The number of hospital discharges increased slightly from 1997 to 2011/2012. The figures are far above the OECD average [9]. Reference [6] shows an increasing difference between the number of hospital discharges and number of hospital patients. The study interprets this as a sign of case splitting. But systematic evidence on the role of case splitting to maximise revenue is very scanty. The LKF-coding system makes this strategy profitable. Case splitting influences the flow of funds to hospitals in two ways [10]: (1) Hospitals that shift part of their treatment procedures to pre- or postsurgical stay receive inadequate payments. (2) Future adjustments of the patient classification system will be based on observed resource consumption. Kobel [10] shows that hospitals with lower-than-average resources have higher transfer rates for patients with coronary artery bypass graft surgery.

The length of stay in hospitals decreased slightly and remains near the OECD average. In [11], there is clear econometric evidence that LKF1997 induced a significant reduction in overall length of stay. Thus, we observe significant differences over specific diagnostic groups, indicating that the reduction in length of stay is driven by a few diagnostic groups.

One important characteristic of a DRG-based hospital financing system is its power to predict variations in actual resource use for different diagnostic groups. This is important for macro-efficiency (e.g. avoiding cream skimming, savings on activities to reduce financial risks) and equity reasons (e.g. equity between hospitals and patient groups). The best empirical basis to report evidence on this issue for LKF1997 is the EuroDRG Study [12]. The authors use a standardised empirical procedure to study ten different diagnostic groups and medical procedures (e.g. acute myocardial infarction, hip replacement, stroke, knee replacement) in ten European countries (including Austria) using data from 2008. They present evidence on the statistical power of estimates on resource requirements (e.g. costs or length of stay) when using (1) classifications of the DRG system only, (2) various patient-level characteristics, and (3) both (1) and (2) simultaneously. Unfortunately, with regard to Austria, only the information on length of stay is available, and this clearly is a suboptimal predictor for resource use. The study group reveals a somewhat homogeneous picture. For Austria, the predictive power of DRG classification is low in absolute and relative terms (compared to other countries). The predictive power of (2) and (3) is comparatively much higher for Austria. These judgments are valid for all diagnostic groups. Overall, the results indicate, although weakly, a space to improve the categorisation system used in LKF1997.

Changes in the service structure of the Austrian hospital system (e.g. bed capacities) have been moderate since the implementation of LKF1997. Hofmarcher and Quentin [1] argue that these changes follow a 'linear' reduction approach and that they are not the result of changes in the financing system. Kobel and Theurl [13] analyse this question empirically. By using different indicators for hospital specialisation (e.g. the HerfindahlHirschman index, Theil index, Gini coefficient), they do not find any significant time trend in hospital specialisation during the 2002-2010 period. These findings are in contrast to the empirical picture in more competitive hospital systems. Systematic empirical evidence on the negative side effects of DRG financing [7], such as cream skimming, up-coding, bloody discharge, supplierinduced demand, and skimping, is not presently available for Austria. Kobel and Pfeiffer [5] argue that up-coding is not very common because the classification system aggravates this strategy to increase revenues. The incentives inherent in the financing system back the expectation that supplier-induced demand leads to an unnecessarily high level of hospital admissions.

Some studies have unanimously concluded that LKF1997 improved the macroeconomic efficiency of hospital systems in several directions [1, 2, 5, 6]. This did not hamper the access of patients to the hospital system. Studies also agree that the strong role of state-specific steering areas might reduce the positive effects of the core area of LKF1997. 


\section{Macro-efficiency of the total health care system}

Our assessment of the effects of LKF1997 on the macroefficiency of health care systems (goals e-h) is much more disillusioning. LKF1997 is primarily a reform of the hospital financing system. It does not close the gap between the outpatient and inpatient sectors, nor does it reduce the high affinity of the Austrian health care system to the hospital sector. Social health insurance only pays a block transfer to the hospital systems not linked to the activity levels of the hospital. Any increase in block transfer is tied to the increase in social health insurance revenues. This means that the social health insurance system does not have any morbidity and cost risk in the inpatient sector of the health care system, but has to cover the full morbidity and cost risk in the outpatient sector. This sort of distribution of financial responsibilities causes inefficiencies and leads to substantial conflicts of interest between the stakeholders. A reduction of activities in the inpatient sector reduces the variable costs but does not change the allocation of resources. For the social health insurance system, there is no incentive to transfer services from the hospital to the outpatient sector. For a few years, there have been reform initiatives to tackle the interfaces between inpatient and outpatient care; these are called 'reform pool projects'. Health Funds can allocate 1-2\% of all public spending to such projects. With the exception of a few disease management programmes (e.g. for diabetes care), the acceptance of and drawing on the resources of this programme are humble. In 2009 , only $16 \%$ of the funds allocated to these projects were used. There are plans to apply a DRGbased remuneration system as well in the outpatient health care sector in Austria. These long-term reform perspectives $[1,2]$ point to a more comprehensive planning and management of health care services along with an integrated form of health care financing by bundling the different sources. These plans directly affect the basic governance structure of the Austrian health care system.

\section{Agenda for the future}

New Institutional Economics teaches us that the existing division of (political) property rights stabilises the expectations of stakeholders and clients (patients). However, the existing distribution of regulative power also structures and restricts politically acceptable reform paths for the future. Thus, we conclude that there is a straightforward space of 'evolutionary' performance improvement within the existing framework. However, we do not discuss the technical details of such initiatives laid down in the literature (for details, see $[1,6])$. In our opinion, the Austrian health care system would profit from the following:
- Restructuring the risk equalisation mechanisms. At present, equalisation mechanisms take place within the social health insurance system and the process of hospital financing between states. The first mechanism is at least partially based on the systematic risk factors on the revenue and expenditure sides. The second mechanism only includes the microelements of risk equalisation. An approach that consolidates the existing equalisation mechanisms and aligns them with the regional risk profile would be a better basis for a publicfinanced health care system.

- Centralising important dimensions of performance assessment. The informational basis provided by LKF1997's performance is used primarily at the hospital and state levels. Performance comparisons between states are rare and should be strengthened to create an atmosphere of managed competition. Centralisation at the central state level could also be helpful to control for coding attitudes. Presently, coding is controlled for only at the state level by using different procedures to identify up-coding and sanctioning it.

In sum, the main agenda for the future is reduction of the inefficiency of the overall health care system. This clearly means that the existing division of property rights in the health care sector need to be changed, with deep consequences for the governance structure. The necessary changes, for example, the comprehensive definition of service levels and service quality guaranteed by the public sector, elimination of price distortions between inpatient and outpatient care, and adjustment of service provision in the two sectors, are primarily not a problem of LKF1997, but are deeply rooted in the mode and culture of political decision making in Austria. New Institutional Economics reveals that one can only rarely observe the sufficient mobilisation of political will and authority outside the health care arena to implement 'big-bang reforms'.

\section{References}

1. Hofmarcher, M., Quentin, W.: Austria-health system review. Health Syst Transit 15(7), 1-291 (2013)

2. Theurl, E.: Die Ordnung des Gesundheitswesens. In: Dirninger, C., Nautz, J., Theurl, E., Theurl, T. (eds.) Zwischen Markt und Staat-Geschichte und Perspektiven der Ordnungspolitik in der Zweiten Republik, pp. 451-551. Böhlau Verlag, Wien-KölnWeimar (2007)

3. Theurl, E.: Gesundheitspolitik. In: Kriechbaumer, R., Schausberger, F. (eds.) Die umstrittene Wende-Österreich 2000-2006, pp. 299-329. Böhlau Verlag, Wien-Köln-Weimar (2013)

4. Saltman, R., Duran, A., Dubois, H. (eds.): Governing public hospitals-reform strategies and the movement towards institutional autonomy. European observatory on health systems and policies, Copenhagen (2011) 
5. Kobel, C., Pfeiffer, K.-P.: Austria: inpatient care and the LKF framework. In: Busse, R., Geissler, A., Quentin, W., Wiley, M. (eds.) Diagnosis related groups in Europe-moving towards transparency, efficiency and quality in hospitals, pp. 175-195. Open University Press, Maidenhead (2011)

6. Gesundheit Österreich $\mathrm{GmbH}$ (ed.): Evaluierungsbericht Leistungsorientierte Krankenanstaltenfinanzierung 1997-2007. Wien (2010)

7. Cots, F., Chiarello, P., Salvado, X., Castells, X., Quentin, W.: DRG-based hospital payments: intended and unintended consequences. In: Busse, R., Geissler, A., Quentin, W., Wiley, M. (eds.) Diagnosis related groups in Europe-moving towards transparency, efficiency and quality in hospitals, pp. 76-92. Open University Press, Maidenhead (2011)

8. Statistik Austria: Gesundheitsausgaben in Österreich lt. System of health accounts 1990-2012. http://www.oecd.org/health/healthsystems/oecdhealthdata2013-frequentlyrequesteddata.htm. Accessed 5 June 2014
9. OECD: OECD Health statistics 2013. Frequently requested data. http://www.oecd.org/health/health-systems/oecdhealthdata2013frequentlyrequesteddata.htm. Accessed 5 June 2014

10. Kobel, C.: Case splitting in the Austrian DRG system. In: Kobel C. (ed.) Evaluation of hospital financing instruments-diagnosisrelated Groups, hospital specialisation and bundled payment, unpublished Thesis, pp. 51-61. Innsbruck (2013)

11. Theurl, E., Winner, H.: The impact of hospital financing on the length of stay: evidence from Austria. Health Policy 82, 375-389 (2007)

12. Busse, R., Geissler, A., Mason, A., Or, Z., Scheller-Kreinsen, D., Street, A.: Diagnosis-related groups in Europe (EuroDRG): do they explain variations in hospital costs and length of stay across patients and hospitals? Health Econ 21, 2 (2012)

13. Kobel, C., Theurl, E.: Hospital specialization within a DRGframework: the Austrian case. Working papers in economics and statistics, University of Innsbruck, 06/2013 